\title{
Relationship between cytokine gene polymorphisms and acute rejection following liver transplantation
}

\author{
X.X. Zhang ${ }^{1}$, R.J. Bian' ${ }^{2}$ J. Wang ${ }^{3}$ and Q.Y. Zhang ${ }^{4}$ \\ ${ }^{1}$ Operating Room, Tangshan Worker's Hospital, Tangshan, Hebei, China \\ ${ }^{2}$ Neurology, Women \& Infants Hospital, Oftangshan, Hebei, China \\ ${ }^{3}$ Intervention Department, Tangshan Worker's Hospital, Tangshan, Hebei, China \\ ${ }^{4}$ Hepatobiliary Surgery, Tangshan City People's Hospital, Cancer Hospital, \\ Tangshan, Hebei, China
}

Corresponding author: X.X. Zhang

E-mail: zhangxiaoxia_1@163.com

Genet. Mol. Res. 15 (2): gmr.15027599

Received September 9, 2015

Accepted December 7, 2015

Published April 25, 2016

DOI http://dx.doi.org/10.4238/gmr.15027599

\begin{abstract}
Acute rejection (AR) recurrence after liver transplantation (LT) is one of the major complications that leads to chronic graft dysfunction. It has been reported that the polymorphisms in some cytokine genes are associated with human liver allograft rejection. This study mainly investigated the associations between polymorphisms in the genes encoding interleukin-10 (IL10), transforming growth factor- $\beta 1$ (TGFB1), and tumor necrosis factor- $\alpha(T N F)$, and the risk of AR recurrence. We enrolled $359 \mathrm{LT}$ recipients; they were divided into two groups: an AR group $(\mathrm{N}=165)$ and a non-AR group $(\mathrm{N}=194)$ according to whether they experienced rejection within the first month following liver transplantation. After providing informed consent, blood was collected and DNA was extracted. The single nucleotide polymorphisms of IL10 (-1082, -819, and -592), TGFBI (+869 and +915), and TNF (-308) were investigated according to the methods used in previous studies. A significant difference was observed in the
\end{abstract}


distribution of allelic frequencies at position +869 in $T G F B 1$ between the $A R$ and non-AR groups $(P=0.000)$. However, no significant differences $(\mathrm{P}>0.05)$ were found in the genotype distributions in IL10,TNF, and $T G F B 1$ between the AR and non-AR groups. Our study suggests that the +869 gene polymorphism of $T G F B 1$ is significantly associated with liver graft rejection, while the other gene polymorphisms investigated in IL10, $T N F$, and $T G F B 1$ are probably not risk factors for AR in LT recipients.

Key words: Cytokines; Liver transplantation; Acute rejection; Single nucleotide polymorphism

\section{INTRODUCTION}

Liver transplantation is considered an effective therapy for severe liver disease, but graft dysfunction occurs in up to $13 \%$ of patients during the first year following transplantation, and rises to $35 \%$ after 5 years (Keeffe, 1999; Yu et al., 2001). Graft rejection is one of the major immunological complications following liver transplantation (Zheng et al., 2006). It is well known that modulation of the immune response, both cellular and humoral, is primarily controlled by various cytokines. These cytokines influence cellular activation, differentiation, and function. Therefore, cytokines play an important role in the immunological events following transplantation, and are intimately implicated in graft rejection.

Thelper subtype 1 (TH1)-type proinflammatory cytokines, such as interleukin-2 (IL-2), interferon- $\gamma($ IFN- $\gamma$ ), and tumor necrosis factor- $\alpha$ (TNF- $\alpha$ ), are associated with graft rejection, whereas TH2-type cytokines such as IL-10 have been associated with graft tolerance (Platz et al., 1996; Shi et al., 2008; Zhang and Sun, 2010). Although some studies have shown an effect on rejection (Warlé et al., 2002; Rattanasiri et al., 2013), others have shown no association (Conti et al., 1998; Xie et al., 2008). The regulatory-type cytokines, such as transforming growth factor- $\beta 1$ (TGF- 31 ), may influence both TH1- and TH2-type cytokines in the immune response (Liu et al., 2009), and some researchers have reported that they are upregulated in rejection (Eikmans et al., 2002), while others have reported no relationship (Eurich et al., 2011; Rattanasiri et al., 2013). To date, studies on the association between cytokine gene polymorphisms and graft rejection have focused mainly on the cytokines mentioned above, in which serum or plasma levels or messenger RNA expression levels were found to correlate with rejection.

In liver transplantation, it is unknown which cytokines may function as initiator or effector cytokines in human liver graft rejection. We hypothesized that polymorphisms in a large array of TH1-, TH2-, and regulatory-type cytokines may have a role in the development of acute rejection following liver transplantation. We investigated the following specific cytokine gene polymorphisms and their relationship with transplant outcome: IL10 (-1082, -819, and -592), TGFB1 (+869 and +915), and TNF (-308). The aim of this study was to determine whether associations exist between polymorphisms in TH1-, TH2-, or regulatorytype cytokine genes (IL10,TNF, and TGFBI), and acute liver graft rejection.

\section{MATERIAL AND METHODS}

\section{Subjects}

A total of 359 patients who had undergone liver transplantation in our hospital between 
2013 and 2015 were enrolled in this study. In our patient group, rejection episodes usually took place within the first month following transplantation, whereas a few patients also experienced rejection later. Therefore, we defined rejectors as patients who experienced rejection within the first months following liver transplantation [acute rejection (AR), $N=165$ ], whereas those who did not experience rejection within the first month were termed non-rejectors (non-AR, $\mathrm{N}$ = 194). We did not further segregate rejectors based on severity or number of rejection episodes. All participants provided written informed consent and the study was approved by the Ethics Committee of our hospital.

\section{Polymorphism genotyping}

Blood samples $(5 \mathrm{~mL})$ were taken from all subjects by venipuncture and stored in ethylenediaminetetraacetic acid (EDTA) tubes for total genomic DNA extraction using a QIAamp DNA Blood Mini Kit (Qiagen, Hilden, Germany). Sample concentrations were determined with ultraviolet spectrometry by measuring absorbance at $260 \mathrm{~nm}\left(\mathrm{~A}_{260}\right)$. Purity was determined by the $\mathrm{A}_{260} / \mathrm{A}_{280}$ ratio. Samples were diluted to a standard concentration and stored at $-20^{\circ} \mathrm{C}$.

Gene polymorphisms for IL10 (Edwards-Smith et al., 1999), TNF (Lympany et al., 1998), and TGFB1 (Powell et al., 2000) were detected using polymerase chain reaction (PCR)based methods, as described previously.

\section{Statistical analysis}

All single nucleotide polymorphism (SNP) data were evaluated for agreement with the Hardy-Weinberg equilibrium. Data are reported as median and range or means and standard deviation (SD). Data were analyzed using the chi-square test and the Fisher exact test where appropriate. Differences in the frequencies of cytokine gene polymorphisms between the AR and non-AR groups were compared using logistic regression analysis. All tests were twotailed and $95 \%$ confidence intervals are provided. Statistical analysis was performed by using the SPSS version 20.0 software. A P value $<0.05$ was considered statistically significant.

\section{RESULTS}

\section{TNF polymorphism}

The results are shown in Table 1, which presents the genotype and allele frequencies of the $\mathrm{G}$ and A alleles of the $T N F-308 \mathrm{G} / \mathrm{A}$ polymorphism in the AR and non-AR groups. No significant differences $(\mathrm{P}=0.317)$ were identified in the genotype or allele frequencies in the $\mathrm{G}$ and $\mathrm{A}$ alleles of the $-308 \mathrm{G} / \mathrm{A}$ polymorphism when the AR and non-AR groups were compared.

\section{IL10 polymorphisms}

The frequencies of the genotypes/alleles $-1082 \mathrm{~A} / \mathrm{G},-819 \mathrm{C} / \mathrm{T}$, and $-592 \mathrm{C} / \mathrm{A}$ in $I L 10$ are presented in Table 2. No significant differences $(\mathrm{P}=0.297, \mathrm{P}=0.801$, and $\mathrm{P}=0.515)$ were identified in the frequencies of the three polymorphisms when the AR and non-AR groups were compared. 
Table 1. Genotype and allele frequencies of the tumor necrosis factor- $\alpha$ gene $(T N F)$ promoter region polymorphism in the acute rejection (AR) group compared with the non-AR group.

\begin{tabular}{|c|c|c|c|c|c|}
\hline \multirow[t]{2}{*}{ Genotype } & AR & Non-AR & \multicolumn{2}{|c|}{ Control $v s$ patients } & \multirow[t]{2}{*}{ P value } \\
\hline & \multicolumn{2}{|c|}{$\mathrm{N}(\%)$} & OR & $95 \% \mathrm{CI}$ & \\
\hline \multicolumn{6}{|l|}{$T N F-308$} \\
\hline GG & 97 (58.79) & $105(54.12)$ & & & \\
\hline GA & $64(38.79)$ & $81(41.75)$ & 1.169 & $0.762-1.795$ & 0.475 \\
\hline AA & $4(2.42)$ & $8(4.13)$ & 1.848 & $0.539-6.331$ & 0.329 \\
\hline Total & 165 & 194 & & & \\
\hline Allele & \multicolumn{2}{|c|}{ (Frequency) } & & & \\
\hline $\mathrm{G}$ & $258(0.78)$ & $291(0.75)$ & 1.042 & $0.843-1.691$ & \multirow[t]{2}{*}{0.317} \\
\hline A & $72(0.22)$ & $97(0.25)$ & 0.837 & $0.668-1.140$ & \\
\hline
\end{tabular}

$\mathrm{OR}=$ odds ratio $; 95 \% \mathrm{CI}=$ confidence interval.

Table 2. Genotype and allele frequencies of the interleukin-10 gene (IL10) promoter region polymorphisms in the acute rejection (AR) group compared with the non-AR group.

\begin{tabular}{|c|c|c|c|c|c|}
\hline \multirow[t]{2}{*}{ Genotype } & AR & Non-AR & \multicolumn{2}{|c|}{ Control $v s$ patients } & \multirow[t]{2}{*}{$P$ value } \\
\hline & \multicolumn{2}{|c|}{$\mathrm{N}(\%)$} & OR & $95 \% \mathrm{CI}$ & \\
\hline \multicolumn{6}{|l|}{ IL10 -1082 } \\
\hline AA & $141(85.45)$ & $170(87.63)$ & & & \\
\hline $\mathrm{AG}$ & $20(12.12)$ & $23(11.86)$ & 0.954 & $0.503-1.808$ & 0.885 \\
\hline GG & $4(2.42)$ & $1(0.52)$ & 0.207 & $0.023-1.876$ & 0.162 \\
\hline Total & 165 & 194 & & & \\
\hline Allele & \multicolumn{2}{|c|}{ (Frequency) } & & & \\
\hline A & $302(0.92)$ & $363(0.94)$ & 0.978 & $0.938-1.020$ & \multirow[t]{2}{*}{0.297} \\
\hline $\mathrm{G}$ & $28(0.08)$ & $25(0.06)$ & 1.317 & $0.784-2.213$ & \\
\hline \multicolumn{6}{|l|}{ IL10 -819 } \\
\hline $\mathrm{CC}$ & $93(56.36)$ & $116(59.79)$ & & & \\
\hline $\mathrm{CT}$ & $60(36.37)$ & $64(32.99)$ & 0.855 & $0.548-1.335$ & 0.491 \\
\hline TT & $12(7.27)$ & $14(7.22)$ & 1.069 & $0.482-2.371$ & 0.870 \\
\hline Total & 165 & 194 & & & \\
\hline Allele & \multicolumn{2}{|c|}{ (Frequency) } & & & \\
\hline $\mathrm{T}$ & $213(0.75)$ & $244(0.76)$ & 0.988 & 0.896-1.088 & \multirow[t]{2}{*}{0.801} \\
\hline $\mathrm{C}$ & $84(0.25)$ & $92(0.24)$ & 1.033 & $0.803-1.328$ & \\
\hline \multicolumn{6}{|l|}{ IL10 -592 } \\
\hline $\mathrm{CC}$ & $109(66.06)$ & $109(56.19)$ & & & \\
\hline $\mathrm{CA}$ & $48(29.09)$ & $69(35.57)$ & 1.437 & $0.913-2.264$ & 0.117 \\
\hline AA & $8(4.85)$ & $16(8.24)$ & 2.000 & $0.822-4.867$ & 0.127 \\
\hline Total & 165 & 194 & & & \\
\hline Allele & \multicolumn{2}{|c|}{ (Frequency) } & & & \\
\hline $\mathrm{C}$ & $205(0.81)$ & $287(0.74)$ & 1.030 & $0.942-1.126$ & \multirow[t]{2}{*}{0.515} \\
\hline A & $64(0.19)$ & $101(0.26)$ & 0.914 & $0.696-1.199$ & \\
\hline
\end{tabular}

$\mathrm{OR}=$ odds ratio $; 95 \% \mathrm{CI}=$ confidence interval.

\section{TGFB1 polymorphisms}

Table 3 presents the genotype and allele frequencies of TGFB1 $+869 \mathrm{C} / \mathrm{T}$ and $+915 \mathrm{G} / \mathrm{C}$ polymorphisms in the AR and non-AR groups. No significant differences (P $=0.260$ ) were identified in the genotype or allele frequencies of $\mathrm{C}$ and $\mathrm{T}$ alleles in the $+915 \mathrm{C} / \mathrm{T}$ polymorphism, while the genotype and allele frequencies in the $+869 \mathrm{C} / \mathrm{T}$ polymorphism showed a statistically significant difference when the AR and non-AR groups were compared $(\mathrm{P}<0.05)$. 
Table 3. Genotype and allele frequencies of the transforming growth factor- $\beta 1$ gene (TGFB1) promoter region polymorphisms in the acute rejection (AR) group compared with the non-AR group.

\begin{tabular}{|c|c|c|c|c|c|}
\hline \multirow[t]{2}{*}{ Genotype } & $\mathrm{AR}$ & Non-AR & \multicolumn{2}{|c|}{ Control $v s$ patients } & \multirow[t]{2}{*}{ P value } \\
\hline & \multicolumn{2}{|c|}{ N (\%) } & $\mathrm{OR}$ & $95 \% \mathrm{CI}$ & \\
\hline \multicolumn{6}{|c|}{$T G F B 1+869$} \\
\hline $\mathrm{CC}$ & $16(9.70)$ & $69(35.57)$ & & & \\
\hline $\mathrm{CT}$ & $73(44.24)$ & $77(39.69)$ & 0.245 & $0.13-0.46$ & $0.000^{*}$ \\
\hline TT & $76(46.06)$ & $48(24.74)$ & 0.146 & $0.076-0.281$ & $0.000^{*}$ \\
\hline Total & 165 & 194 & & & \\
\hline Allele & \multicolumn{2}{|c|}{ (Frequency) } & & & \\
\hline $\mathrm{C}$ & $105(0.32)$ & $215(0.55)$ & 0.574 & $0.479-0.688$ & \multirow[t]{2}{*}{$0.000 *$} \\
\hline $\mathrm{T}$ & $225(0.68)$ & $173(0.45)$ & 1.529 & $1.338-1.747$ & \\
\hline \multicolumn{6}{|c|}{$T G F B I+915$} \\
\hline GG & $145(87.88)$ & $162(83.51)$ & & & \\
\hline CG & $20(12.12)$ & $32(16.49)$ & 1.432 & $0.784-2.615$ & 0.242 \\
\hline $\mathrm{CC}$ & $0(0)$ & $0(0)$ & 0 & 0 & 0 \\
\hline Total & 165 & 194 & & & \\
\hline Allele & \multicolumn{2}{|c|}{ (Frequency) } & & & \multirow{3}{*}{0.260} \\
\hline $\mathrm{G}$ & $310(0.94)$ & $356(0.92)$ & 1.024 & $0.983-1.066$ & \\
\hline $\mathrm{C}$ & $20(0.06)$ & $32(0.08)$ & 0.735 & $0.429-1.260$ & \\
\hline
\end{tabular}

$\mathrm{OR}=$ odds ratio $; 95 \% \mathrm{CI}=$ confidence interval; *statistically significant.

\section{DISCUSSION}

Cytokines are potent immunomodulatory molecules that take part in inflammation and the immune response. This study investigated whether a genetic predisposition involving polymorphisms of TH1-, TH2-, or regulatory-type cytokine genes was associated with rejection following human liver transplantation. Several polymorphisms in cytokine genes have been investigated for their possible relationship with cytokine production (Platz et al., 1996; Warlé et al., 2002; Shi et al., 2008; Liu et al., 2009; Zhang and Sun, 2010; Rattanasiri et al., 2013) and graft rejection. Polymorphisms of $I L 10, T N F$, and TGFB1 have been reported to be closely linked to AR (Bathgate et al., 2000; Jonsson et al., 2001; Mas et al., 2004; Azarpira et al., 2013). However, the results are controversial (Eurich et al., 2011; Rattanasiri et al., 2013). This study showed significant correlation between the SNPs ILI0 -1082 and TGFBI +869 and AR, but there was no significant correlation between the SNPs of the other genes and AR.

Our results showed that the polymorphism in $T N F$, a TH1-type cytokine gene, did not correlate significantly with acute liver graft rejection, even though some studies on the relationship between $T N F$ gene polymorphisms and graft rejection have shown that the -308 genotype is associated with liver allograft rejection. Other researchers have produced similarly inconsistent results; Jonsson et al. (2001) reported that the -308 polymorphism in the TNF gene promoter correlated with graft rejection, while Warlé et al. (2002) did not agree with the result.

IL-10 is a TH2-type anti-inflammatory cytokine that regulates immunoproliferation, the inflammatory response, and allograft tolerance. In this study, we found there was no association between the IL10 -1082 allele and risk of AR. This result is partially in line with the results from other studies (Liu et al., 2011, 2012). In contrast, the authors of other studies (Mas et al., 2004; Liu et al., 2011) found that there was an association between the IL10 SNP at position -1082 and graft rejection. The results from these studies and those from our research were strongly influenced by patient ethnicity. In the study reported by Mas et al. (2004), the IL10 AA genotype in Caucasians at position -1082 occurred in $32.5 \%$ of patients, while in Han Chinese (Xie et al., 2008) it occurred in $88.2 \%$ of patients; the figure was $85.45 \%$ in our study. 
Therefore, apparent discrepancies might be due to cytokine frequency differences among the different ethnic backgrounds.

TGF- $\beta 1$ is a regulatory cytokine that can influence the Th1 and Th2 reactions of the immune response. In this study, we found that the $T G F B 1+869$ polymorphism was significantly associated with liver graft rejection, which was consistent with the study by Warlé et al. (2002). It is possible that TGF- $\beta 1$ itself contributes to the rejection reaction. Moreover, studies have shown that TGF- $\beta 1$ is related to chronic rejection of liver, heart, kidney, and lung grafts (Suthanthiran et al., 2000; Warlé et al., 2002). In addition, the mRNA levels of TGFB1 were elevated in acute rejection biopsy specimens from heart transplant recipients, and TGF- $\beta 1$ protein expression levels increased in kidney biopsy specimens during AR (Shihab et al., 1995). Perhaps TGF- $\beta 1$ itself is directly involved in AR through its role in apoptosis.

In conclusion, this study suggested that the $T G F B 1+869$ cytokine polymorphism might play a role in AR in liver transplant patients, while the polymorphisms in the IL10 and $T N F$ genes did not have a major association with AR. Further studies with larger sample sizes are required to confirm this association and to explore the role of these polymorphisms in the regulation of cytokine gene expression.

\section{Conflicts of interest}

The authors declare no conflict of interest.

\section{REFERENCES}

Azarpira N, Nikeghbalian S, Kazemi K, Geramizadeh B, et al. (2013). Association of increased plasma interleukin-6 and TNF- $\alpha$ levels in donors with the complication rates in liver transplant recipients. Int. J. Organ Transplant. Med. 4: 9-14.

Bathgate AJ, Pravica V, Perrey C, Therapondos G, et al. (2000). The effect of polymorphisms in tumor necrosis factoralpha, interleukin-10, and transforming growth factor-beta1 genes in acute hepatic allograft rejection. Transplantation 69: 1514-1517. http://dx.doi.org/10.1097/00007890-200004150-00054

Conti F, Boulland ML, Leroy-Viard K, Chereau C, et al. (1998). Low level of interleukin 10 synthesis during liver allograft rejection. Lab. Invest. 78: 1281-1289.

Edwards-Smith CJ, Jonsson JR, Purdie DM, Bansal A, et al. (1999). Interleukin-10 promoter polymorphism predicts initial response of chronic hepatitis $C$ to interferon alfa. Hepatology 30: 526-530. http://dx.doi.org/10.1002/hep.510300207

Eikmans M, Sijpkens YW, Baelde HJ, de Heer E, et al. (2002). High transforming growth factor-beta and extracellular matrix mRNA response in renal allografts during early acute rejection is associated with absence of chronic rejection. Transplantation 73: 573-579. http://dx.doi.org/10.1097/00007890-200202270-00016

Eurich D, Bahra M, Boas-Knoop S, Lock JF, et al. (2011). Transforming growth factor $\beta 1$ polymorphisms and progression of graft fibrosis after liver transplantation for hepatitis C virus - induced liver disease. Liver Transpl. 17: 279-288. http://dx.doi.org/10.1002/lt.22190

Jonsson JR, Hong C, Purdie DM, Hawley C, et al. (2001). Role of cytokine gene polymorphisms in acute rejection and renal impairment after liver transplantation. Liver Transpl. 7: 255-263. http://dx.doi.org/10.1053/jlts.2001.22450

Keeffe EB (1999). Patient selection and listing policies for liver transplantation. J. Gastroenterol. Hepatol. 14 (Suppl): S42-S47. http://dx.doi.org/10.1046/j.1440-1746.1999.01876.x

Liu F, Wei Y, Li B and Yan L (2011). Need for the clarification of data in a recent meta-analysis about cytokine gene polymorphisms and acute liver graft rejection. Liver Transpl. 17: 875-876. http://dx.doi.org/10.1002/lt.22308

Liu F, Li B, Wang WT, Wei YG, et al. (2012). Interleukin-10-1082G/A polymorphism and acute liver graft rejection: a meta-analysis. World J. Gastroenterol. 18: 847-854. http://dx.doi.org/10.3748/wjg.v18.i8.847

Liu XX, Feng-Ming LI, Chen YM and Wang XL (2009). Effects of transforming growth factor $\beta-1$ on proliferation and activation of T lymphocytes in peripheral blood in vitro. J. Practical Med. 20: 3373-3375.

Lympany PA, Avila JJ, Mullighan C, Marshall S, et al. (1998). Rapid genotyping of transforming growth factor beta1 gene polymorphisms in a UK Caucasoid control population using the polymerase chain reaction and sequence-specific primers. Tissue Antigens 52: 573-578. http://dx.doi.org/10.1111/j.1399-0039.1998.tb03089.x 
Mas VR, Fisher RA, Maluf DG, Archer KJ, et al. (2004). Polymorphisms in cytokines and growth factor genes and their association with acute rejection and recurrence of hepatitis $\mathrm{C}$ virus disease in liver transplantation. Clin. Genet. 65 : 191-201. http://dx.doi.org/10.1111/j.0009-9163.2004.00208.x

Platz KP, Mueller AR, Rossaint R, Steinmüller T, et al. (1996). Cytokine pattern during rejection and infection after liver transplantation - improvements in postoperative monitoring? Transplantation 62: 1441-1450. http://dx.doi. org/10.1097/00007890-199611270-00011

Powell EE, Edwards-Smith CJ, Hay JL, Clouston AD, et al. (2000). Host genetic factors influence disease progression in chronic hepatitis C. Hepatology 31: 828-833. http://dx.doi.org/10.1053/he.2000.6253

Rattanasiri S, McDaniel DO, McEvoy M, Anothaisintawee T, et al. (2013). The association between cytokine gene polymorphisms and graft rejection in liver transplantation: a systematic review and meta-analysis. Transpl. Immunol. 28: 62-70. http://dx.doi.org/10.1016/j.trim.2012.10.003

Shi LB, Zhang HW and Cui YY (2008). [Implication of different expression of IL-2 mRNA and IL-10 mRNA in CD4(+) $\mathrm{CD} 25(+) \mathrm{T}$ cell induced immune tolerance of liver transplantation in rat]. Zhongguo Wei Zhong Bing Ji Jiu Yi Xue 20: $257-260$.

Shihab FS, Yamamoto T, Nast CC, Cohen AH, et al. (1995). Transforming growth factor-beta and matrix protein expression in acute and chronic rejection of human renal allografts. J. Am. Soc. Nephrol. 6: 286-294.

Suthanthiran M, Li B, Song JO, Ding R, et al. (2000). Transforming growth factor-beta 1 hyperexpression in AfricanAmerican hypertensives: A novel mediator of hypertension and/or target organ damage. Proc. Natl. Acad. Sci. USA 97: 3479-3484.

Warlé MC, Farhan A, Metselaar HJ, Hop WC, et al. (2002). Cytokine gene polymorphisms and acute human liver graft rejection. Liver Transpl. 8: 603-611. http://dx.doi.org/10.1053/jlts.2002.33967

Xie HY, Wang WL, Yao MY, Yu SF, et al. (2008). Polymorphisms in cytokine genes and their association with acute rejection and recurrence of hepatitis B in Chinese liver transplant recipients. Arch. Med. Res. 39: 420-428. http:// dx.doi.org/10.1016/j.arcmed.2008.01.003

Yu AS, Ahmed A and Keeffe EB (2001). Liver transplantation: evolving patient selection criteria. Can. J. Gastroenterol. 15: 729-738.

Zhang L and Sun WB (2010). Th1/Th2 Type Cytokines and Graft Rejection and Immune Tolerance. Medical Recapitulate 16: 501-503.

Zheng S, Chen Y, Liang T, Lu A, et al. (2006). Prevention of hepatitis B recurrence after liver transplantation using lamivudine or lamivudine combined with hepatitis B Immunoglobulin prophylaxis. Liver Transpl. 12: 253-258. http://dx.doi.org/10.1002/lt.20701 